NBER WORKING PAPER SERIES

\title{
ASYMMETRIC INFORMATION AND THE DEMAND FOR VOLUNTARY HEALTH INSURANCE IN EUROPE
}

\author{
Kristian Bolin \\ Daniel Hedblom \\ Anna Lindgren \\ Bjorn Lindgren \\ Working Paper 15689 \\ http://www.nber.org/papers/w15689
}

\section{NATIONAL BUREAU OF ECONOMIC RESEARCH 1050 Massachusetts Avenue}

In this his paper, we used data from theampridge MAA O2 SPPARE 2004. This release is preliminary

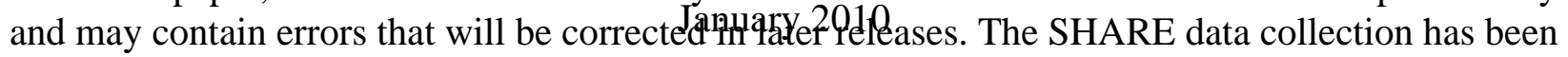
primarily funded by the European Commission through the 5th framework program (project QLK6-CT-2001-00360 in the thematic program Quality of Life program area). Additional funding came from the US National Institute on Aging (U01 AG09740-13S2, P01 AG005842, P01 AG08291, P30 AG12815, Y1-AG4553-01 and OGHA 04-064). Data collection in Austria (through the Austrian Science Foundation, FWF), Belgium (through the Belgian Science Policy Administration) and Switzerland (through BBW/OFES/UFES) was nationally funded. The SHARE data set is introduced in Börsch-Supan et al. (2005); methodological details are contained in Börsch-Supan and Jürges (2005). Additional funding for the Swedish participation in the SHARE data collection project came from the Bank of Sweden Tercentenary Foundation, the Swedish Council for Working Life and Social Research, and the Swedish Social Insurance Agency. The research reported in this paper was supported by grants from the Swedish Council for Working Life and Social Research and the Trygg Hansa Research Foundation, which is gratefully acknowledged. A previous version of this article was presented at the 2009 SHARE User Conference in Mainz, Germany. The authors would like to thank seminar participants for valuable comments. The views expressed herein are those of the authors and do not necessarily reflect the views of the National Bureau of Economic Research.

NBER working papers are circulated for discussion and comment purposes. They have not been peerreviewed or been subject to the review by the NBER Board of Directors that accompanies official NBER publications.

(C) 2010 by Kristian Bolin, Daniel Hedblom, Anna Lindgren, and Bjorn Lindgren. All rights reserved. Short sections of text, not to exceed two paragraphs, may be quoted without explicit permission provided that full credit, including $\odot$ notice, is given to the source. 
Asymmetric Information and the Demand for Voluntary Health Insurance in Europe

Kristian Bolin, Daniel Hedblom, Anna Lindgren, and Bjorn Lindgren

NBER Working Paper No. 15689

January 2010

JEL No. D82,I1

\begin{abstract}
Several past studies have found health risk to be negatively correlated with the probability of voluntary health insurance. This is contrary to what one would expect from standard textbook models of adverse selection and moral hazard. The two most common explanations to the counter-intuitive result are either (1) that risk-aversion is correlated with health - i.e. that healthier individuals are also more risk-averse - or (2) that insurers are able to discriminate among customers based on observable health-risk characteristics. We revisited these arguments, using data from the Survey of Health, Ageing and Retirement in Europe (SHARE). Self-assessed health served as an indicator of risk: better health, lower risk. We did, indeed, observe a negative correlation between risk and insurance but found no evidence of heterogeneous risk-preferences as an explanation to our finding.
\end{abstract}

Kristian Bolin

Department of Economics

Lund University

P.O.Box 7082

SE-220 07 Lund

SWEDEN

Kristian.Bolin@luche.lu.se

Daniel Hedblom

Department of Economics

Stockholm University

SE-106 91 Stockholm

Sweden

hedblomdaniel@gmail.com
Anna Lindgren

Centre for Mathematical Sciences

P.O.Box 118

SE- 22100 Lund

SWEDEN

Anna.Lindgren@matstat.lu.se

Bjorn Lindgren

Lund University Biomedical Centre

BMC D1143a

SE-221 84 Lund

SWEDEN

and NBER

Bjorn.Lindgren@med.lu.se 


\section{Introduction}

All health-care policy reforms involving voluntary health insurance need to address the problem of asymmetric information. As a cause of adverse selection and moral hazard, asymmetric information between the buyer and the seller poses a serious problem for the functioning of the voluntary health insurance market. In both research and practice, this problem has chiefly been considered in the context of the United States market for health insurance. Nonetheless, voluntary health insurance exists in all European countries - despite the predominance of social insurance or tax-financed systems. European voluntary health insurance serves many different functions; allowing faster treatment, a broader choice of hospitals, and better amenities. The voluntary contracts generally constitute additional insurance, above and beyond the coverage supplied by the mandatory system. ${ }^{1}$

Policy-makers may view voluntary health insurance as a vehicle for easing the public burden of health-care financing. Several countries have seen attempts to introduce more private elements in the financing of health care, but their share has remained fairly small (OECD, 2004). However, the long-term sustainability of publicly financed health care will soon be challenged by demographic changesmore dramatic in some countries than in others (Klevmarken and Lindgren, 2008). As a result of these changes, the market for voluntary health insurance might drastically aggrandize - not only in Europe but in all OECD countries (OECD, 2004). From a public policy perspective, it is therefore crucial to possess firm knowledge about individual characteristics that are correlates to holdings of voluntary health insurance. Do high-risk individuals self-select into voluntary health insurance or are insurers able to discriminate among customers and offer different insurance contracts?

\footnotetext{
${ }^{1}$ Be that social insurance, a national health-service system, or-for that matter-mandatory private insurance as in Switzerland.
} 
We addressed this question with an empirical investigation of the determinants of voluntary health insurance holdings in ten European countries, using data from the Survey of Health, Ageing and Retirement in Europe (SHARE). The SHARE database offers rich information on health and health-related behavior of the 50+ population of a number of European countries. ${ }^{2}$ In particular, we analyzed the correlation between health-related risk and holdings of voluntary health insurance. If the European markets for voluntary health insurance were characterized by asymmetric information, we would expect people with higher ex ante health-risk levels to be more inclined to purchase voluntary health insurance than their lowrisk counterparts. By adopting the not too far-fetched assumption that future health (and thereby also future healthcare needs) is partly determined by a stochastic process with a variance depending negatively on current health, we can view the risk insured by voluntary health insurance as depending negatively on health.

A well-known result from the theoretical insurance literature states that when asymmetric information prevails, it will not be profitable for an insurer to offer all individuals a contract based on the average risk of the population as a whole (see, for example, Rotschild and Stiglitz, 1976). Because of the lower expected benefit of buying insurance for individuals with relatively low risk, they are more likely to remain uninsured than individuals with relatively high risks. The insurance pool will eventually consist of an adverse selection of the population with a higher-than-average risk level. As a consequence, the insurer will have to increase premiums in order to cover increasing costs, which will force even more low-risk

\footnotetext{
${ }^{2}$ See the web page, http://www.share-project.org/, and the next section on the data used in this study. SHARE data has recently been used, for example, in studies of the utilization of formal and informal care among the elderly of Europe (Bolin et al., 2008; Bonsang 2009), the utilization of physician services (Bolin et al., 2009), education-related inequality in physical health (Jürges, 2009), supply and demand effects on influenza vaccination (Maurer,,2009), socio-economic status and health inequalities in Mediterranean countries (Verropoulou and Tsimbos, 2007), socio-economic status and waiting times (Siciliani and Verzulli, 2009), impact of children on their parents' mental health (Buber and Engelhardt, 2008), and the health of immigrants in Europe (Solé-Auró and Crimmins, 2008).
} 
individuals out of the insurance pool. Consequently, standard textbook models of adverse selection and moral hazard predict that the (ex-post) average risk-level among those holding voluntary insurance to be higher than the average population risk. We would, therefore, expect a positive correlation between health-risk and voluntary health insurance and-since health-risk was assumed to be negatively dependent on health $-\mathrm{a}$ negative correlation between self-assessed health and insurance.

Even though some past empirical studies have, indeed, found support for the theoretical prediction of a positive correlation between risk and insurance- for example, with data from the British annuity market (Finkelstein and Poterba, 2004), and the U.S. market for supplemental medical insurance for the elderly (Ettner, 1997) - empirical studies of the demand for voluntary health insurance generally fail to find support for such a relationship (see, for example, Cawley and Philipson, 1999; Chiappori and Salanie, 2000; Finkelstein and McGarry, 2003; and Doiron et al., 2008). Insured tend to be healthier, younger, more educated, and richer than the uninsured (Doiron et al., 2008). Low-risk individuals simply seem to be more willing to purchase coverage in addition to the level offered by the mandatory scheme.

The empirical literature has furnished two distinct sets of explanations to this finding. First, individual risk may be correlated with risk preference (Finkelstein and McGarry, 2003; Doiron et al., 2008). This would mean that individuals with better health are more risk-averse than individuals with relatively bad health. The rationale for this assumption is that, the more risk-averse an individual becomes, the more inclined he or she will be to undertake precautionary measures with regards to health; to invest more in health. These health-investments may take the form of exercise or absence of smoking or alcohol (i.e. lack of disinvestments). Greater investments in health lead to both better self-assessed health and fewer observable medical conditions. Since risk-averse individuals are also more likely to obtain voluntary health insurance, the observed negative correlation between 
risk and insurance might possibly be an effect of those individuals' risk preferences. If this is the case, we would expect observable health conditionssuch as diagnosed diseases - to decrease self-assessed health but to increase the probability of insurance. A competing explanation to the findings that individual risk seems to be negatively correlated with insurance is that insurers are able to offer more attractive contracts to low-risk individuals, by discriminating on the basis of observable characteristics (Shmueli, 2001). If so, we would expect observable health conditions to decrease both self-assessed health and the probability of insurance.

Our study was essentially carried out in a two-step process. In the first step, we estimated a series of probit-models to see whether we could find the negative correlation between health-risk and probability of insurance. Self-assessed health served as an indicator of risk: better health, lower risk. In order to limit the effects of framing and at what point in the SHARE survey questionnaire the question about self-assessed health was asked, two different versions of self-assessedhealth questions were used. We started with a simple specification of the estimation model, comprising only health-risk as an explanatory variable. In similarity to previous studies, we-indeed-found a negative correlation, irrespective of version. We then estimated a series of specifications, in which subsequent specification comprised a larger set of explanatory variables (country, demographics, health and risk-related behavior), chosen on the basis of previous empirical research (Ettner, 1997; Hurd and McGarry, 1997; Smith and Kington, 1997; Perry and Rosen, 2004; Doiron et al., 2008). The negative correlation persisted.

In the second step, we tried to answer the question whether the negative correlation was a result of heterogeneous risk preferences among insured individuals or screening on behalf of the insurer. To do so, we omitted the selfassessed health variables from the probit-model and estimated a model with only countries, demographics, and observable health characteristics as explanatory 
variables. Subsequently, we estimated an ordered probit model with the same explanatory variables, but with self-assessed health as dependent variable. This process was carried out on both versions of the questions. By comparing the effect of observable health characteristics on self-assessed health to those on the probability of insurance, we concluded that observable conditions (e.g. diagnosed chronic conditions) generally seemed to reduce both self-assessed health and the probability of insurance. Hence, we did not find support for the heterogeneous risk-preference explanation of the negative correlation between risk and insurance.

\section{Data: sources and description}

All data were obtained from the SHARE - a multidisciplinary and cross-national micro database. The SHARE follows the design of the US Health and Retirement Study (HRS), and the English Longitudinal Study of Ageing (ELSA). ${ }^{3}$ The database currently contains information from 12 countries, comprising a total of approximately 32,000 individuals above 50 years of age and their household members. We used data from 10 of the countries covered by the first wave of SHARE, conducted in 2004: Austria, Belgium, Denmark, France, Germany, Greece, Italy, Spain, Sweden, and Switzerland. ${ }^{4}$ Data from the Netherlands were excluded, because the structure of its health insurance system differs from the other countries to such an extent that it does not allow for a viable comparison. ${ }^{5}$

Our dataset included information on a number of health-related variables (e.g. self-assessed health, chronic symptoms and psychological health), labor-market

\footnotetext{
${ }^{3}$ SHARE data set is introduced in Börsch-Supan, Brugiavini et al. (2005). Methodological details can be found in Börsch-Supan and Jürges (2005).

${ }^{4}$ Since the first wave of SHARE data collection, the Czech Republic, Ireland, Israel, and Poland have joined the SHARE project.

${ }^{5}$ See, for example, Shut and van de Ven (2005) for information about the Dutch health-care system and its recent reforms.
} 
conditions (such as present job characteristics and opportunities to work past retirement age), education, sources of current income, wealth, consumption, etc. The overall response rates varied substantially between countries, ranging from 38 percent in Switzerland to 69 percent in France, with an average for all participating countries of 62 percent.

Data on self-assessed health and holdings of voluntary health insurance were central to our study. However, some individuals did not answer the SHARE questionnaire questions about these two variables. Thus, after omitting observations with missing values, we were left with 25,390 observations. They were unevenly spread among the countries, ranging from 1000 (Switzerland) to 3817 (Belgium).

\subsection{Dependent variable}

The dependent variable measured whether the respondent held any kind of voluntary health insurance. It took the value 1, if the respondent had any voluntary health insurance, and 0 otherwise. In the English language version of the SHARE questionnaire, the question was formulated: "Do you have any voluntary, supplementary or private health insurance for at least one of the following types of care in order to complement for the care offered by the national health service?" (and the corresponding wording for the other languages). The respondent was then free to answer either yes or no to a number of different voluntary health-insurance contracts. The insurance would be either for full hospital costs, drugs expenses, direct access to specialists, extended choice of doctors, or for dental care. Table 1 shows the frequency of voluntary healthinsurance coverage by country. Voluntary coverage varied from 78.7 percent in France to a mere 2.2 percent in Sweden. A total of 6693 (approximately 26.4 percent) individuals in the full dataset had some form of voluntary health insurance. 
[Table 1 about here]

\subsection{Independent variables}

Table 2 provides a list of all independent variables and descriptive statistics. In the first step of the study, we were interested in the effect of health risk on the likelihood of holding voluntary health insurance. In order to infer this effect, we also had to account for other possible determinants. In addition to self-assessed health as an indicator of health-risk, there were three groups of control variables, reflecting demographics, health and health-related behavior, and country.

[Table 2 about here]

\section{Health-risk (self-assessed health)}

The key independent variable was health-risk, for which self-assessed health was used as a proxy. ${ }^{6}$ Two different sets of self-assessed health variables were available and used in parallel estimations. ${ }^{7}$ Thus, all SHARE respondents were asked to report how their health corresponded to two separate sets of given alternatives. This was done both in the beginning and at the end of the physicalhealth module. Following the notation of the SHARE questionnaire, we refer to the two different sets as the "European" and as the "American" version. The order of the two sets of questions was randomized among respondents. In both versions, the question was asked: "Would you say that your health is...". The alternatives

\footnotetext{
${ }^{6}$ Self-assessed health seems to be generally considered to be a reasonable proxy for health risk, with the merit of capturing effects of undiagnosed conditions and social and mental well-being (see, for instance, Wagstaff and van Doorslaer, 1994; Hurd and McGarry, 1995; and Gerdtham et al., 1999).

7 This was done in order to analyze the robustness of results. There may be problems regarding how to interpret responses to the self-assessed questions, of course. Interviews were, for instance, performed in several languages, and there may be systematic variance between countries concerning the way health-related questions were perceived. Moreover, cultural differences among countries may lead to differences in people's propensity to report, for instance, low levels or high levels of health. In addition, previous studies have shown that some individuals tend to change their responses among multiple questions about self-assessed health, depending on how and when in the questionnaire the questions are asked. (Crossley and Kennedy, 2002).
} 
of the European version were: "very good", "good", "fair", "bad" or "very bad"; while the American-version alternatives were: "excellent", "very good", "good health", "fair", and "poor".

[Table 3 about here]

Table 3 presents statistics on voluntary health-insurance coverage by health status, using both the European and the American scale. The medium level of self-assessed health served as reference group both in the "European" version ("fair health") and in the "American" one ("good health").

\section{Observable health conditions and behavioral risk factors}

The health and behavioral risk-related variables included specific dummies for a number of conditions: cancer, heart problems, diabetes, asthma, high blood pressure, and chronic lung diseases. We also included a variable for the respondent's total number of chronic symptoms. In the English version of the questionnaire, the question about chronic conditions was formulated: "Has a doctor ever told you that you had any of the conditions on this card?" The respondent could then answer yes to any of the symptoms.

This group of variables also included a set of dummies for risk-related behavior; smoking, alcohol consumption (more than five times per week), and exercise (simply whether the respondent performed any form of physical activity at least once per week). The corresponding control groups were the people who did not smoke, did not consume alcohol, and did not exercise. Finally, we also included a dummy-variable for depression. This variable was based on a subjective measure; it assumes the value of one, if the respondent answered yes to the question whether he or she had been feeling depressed during the last month. 


\section{Demographics and country}

The demographic control variables included age, education, gender, marital status, employment status, and whether or not the respondent was born in the country of residence. Furthermore, a series of dummy variables was used for different wealth brackets. Wealth was defined as purchasing power parityadjusted household net wealth, and the dummy variables represented intervals between 10th, 25th, 50th 75th and the 90th percentiles. The lowest wealth group (i.e. the first decile) served as reference. We used imputed values constructed by the SHARE team for observations with missing wealth values. ${ }^{8}$

Our measure of education consisted of two dummy variables; one indicating secondary education and the other higher-than-secondary education. Individuals with less-than-secondary education served as the reference group.

Two dummy variables indicated unemployment and self-employment. We expected unemployment to reduce the probability of insurance. Given that a person who runs his own business may risk suffering losses if he or she gets sick, we expected self-employment to have a positive effect.

Country-specific dummy variables were intended to capture effects of differences in health-care or health-care-financing systems as well as in other unobservable factors, such as culture and institutions. As a result of the relatively large number of observations from Germany, we let the country serve as the reference group.

Health care systems in Europe are certainly rather different. Thus, in order to further control for the effect of institutional difference and to perform some robustness checks on our results, we used a number of interaction variables based

\footnotetext{
8 For documentation, see Börsch-Supan and Jürges (2005). The percentage of imputed wealth values for the participating countries (calculated from Börsch-Supan and Jürges 2005) are as follows: Sweden, 6.8\%; Denmark, 7.1\%; Germany, 10.1\%; The Netherlands, 7.7\%; France, 10.9\%; Switzerland, 10.4\%; Austria, 7.5\%; Italy, 7.7\%; Spain, 10.7\%; and Greece, $6.5 \%$.
} 
on the country dummy variables. Each control variable in the "Health and Risk" and "Demographics" groups of Table 2 was multiplied by each country dummy, hence, creating the corresponding interaction variables for each country. In total, we used approximately 250 control variables in the robustness check process.

\section{Model specification and statistical method}

The first step in our analysis consisted of investigating the correlation between health risk and insurance. Thus, following the method of Ettner (1997) and Doiron et al. (2008), we first estimated a specification that contained our healthrisk measures only (self-assessed-health dummies). Then we obtained the subsequent specifications by adding group for group of explanatory variables to the baseline specification. Since the dependent variable was dichotomous, we used a probit-model to estimate each consecutive specification. The objective was to see whether the relationship between risk and insurance disappeared, when more explanatory variables were added.

Model (1) below represents the simplest specification. Throughout, $p_{i}$ is the probability that individual $i$ holds any VHI, and $\varepsilon_{i}$ is an error term. $\hat{H}_{i}$ is a vector of self-assessed health dummies (which may be of either the European or the American formulation). In Model (2), we added the country-specific dummy variables, contained in the vector $\hat{C}_{i}$. In the two subsequent models, a vector $\hat{R}_{i}$, representing health and behavioral risk- factors was added. Model 5 is the full model with all control variables present.

$$
\begin{aligned}
& p_{i}=\beta_{1} \hat{H}_{i}+\varepsilon_{i} \\
& p_{i}=\beta_{1} \hat{H}_{i}+\beta_{2} \hat{C}_{i}+\varepsilon_{i}
\end{aligned}
$$




$$
p_{i}=\beta_{1} \hat{H}_{i}+\beta_{2} \hat{C}_{i}+\beta_{3} \hat{D}_{i}+\varepsilon_{i}
$$

$$
p_{i}=\beta_{1} \hat{H}_{i}+\beta_{2} \hat{C}_{i}+\beta_{4} \hat{R}_{i}+\varepsilon_{i}
$$

$$
p_{i}=\beta_{1} \hat{H}_{i}+\beta_{2} \hat{C}_{i}+\beta_{3} \hat{D}_{i}+\beta_{4} \hat{R}_{i}+\varepsilon_{i}
$$

As a second step, we compared the effect of observable health conditions on the probability of insurance to the effect of the same variables on self-assessed health. Thus, following a method similar the one of Lokshin and Ravallion (2005), we first estimated an ordered probit-model with self-assessed health as dependent variable. Model 6 below represents this specification, where $h_{i}$ is a discrete variable that can assume four different values, each representing one of the health levels. Thereafter, we estimated a probit-model with the same independent variables but with insurance as dependent variable (Model 7).

$$
\begin{aligned}
& h_{i}=\gamma_{1} \hat{C}_{i}+\gamma_{2} \hat{D}_{i}+\gamma_{3} \hat{R}_{i}+\eta_{i} \\
& p_{i}=\gamma_{1} \hat{C}_{i}+\gamma_{2} \hat{D}_{i}+\gamma_{3} \hat{R}_{i}+\eta_{i}
\end{aligned}
$$

\section{Results}

\subsection{Voluntary health insurance and health-risk}

Tables 4 and 5 show the main results in terms of estimated marginal effects from the probit-regressions, utilizing the European and the American versions of the 
self-assessed-health scale, respectively. Each coefficient denotes the effect on the estimated likelihood that the respondent held voluntary health insurance of moving from the baseline risk level, represented by "fair health" in the European and "good health" in the American version, to the corresponding risk-levels. In both cases, increased health-risk means a lower likelihood of holding voluntary health insurance. Our result supports previous findings of a negative correlation between health-risk and voluntary health insurance.

[Table 4 about here]

[Table 5 about here]

In the simplest specification (Model 1), only the variables for self-assessed health (as indicators of risk: better health, lower risk) were included. The coefficients for all variables except "excellent health" in the American version were significant at the $1 \%$ or $10 \%$-level. Moving from fair to very good self-assessed health in the European version increased the probability of voluntary health insurance with approximately 0.17 . Note, however, that the effect was not monotonic. Moving from good to very good health actually decreased the probability of voluntary health insurance.

In Model 2, we added the set of country specific dummy-variables, controlling for institutional differences between the European countries. All coefficients for selfassessed health had the expected signs and were significant at the $1 \%$ level. The effects were monotonic. In the European version, moving from fair health to very good health increased the likelihood of voluntary health insurance with 0.242 . Similarly, moving to the lowest level of self-assessed health (very bad health) decreased the likelihood with 0.249 . The corresponding numbers for the American version were 0.158 and 0.288 . 
In Models 3, 4 and 5, we continued to add groups of control variables. In Model 3, we controlled for demographic effects, while model 4 included observable health factors and risk behavior. Model 5 was the full model with all control variables present. It is evident from tables 4 and 5 that the negative correlation between risk and insurance certainly persisted. The marginal effects on the probability of voluntary health insurance of moving from fair/good to the best category of self-assessed health were, however, reduced to 0.095 and 0.081 . Note, though, that the effect of moving from good health to very good health in the American version was not statistically significant.

\subsection{Robustness checks}

In order to test the robustness of our results, we estimated models 3, 4, and 5 with an additional set of control variables, namely the country specific interaction variables. The rationale was to examine whether the found relationship would vanish once we took into account the additional effect of, for example, being unemployed in a specific country. The results from these probit regressions are shown in table 6 for the European version and table 7 for the American version. Indeed, the positive correlation between self-assessed health and voluntary health insurance holdings, or for that matter, the negative correlation between risk and insurance, seemed to persist. As apparent from tables 6 and 7, the marginal effects were generally reduced slightly, and the p-values were increased for some of the self-reported health levels. Nonetheless, including the interaction variables did not substantially alter the results.

Moreover, we estimated a series of models in which one or more country was omitted. The reason for this was to examine whether results might be driven by a particularly strong effect in a specific country. When doing this, the marginal effects of moving from one self-assessed health level to another were reduced slightly in some cases, but the overall relationship was intact. Finally, we note that 
there were no particular differences with regards to which country that was omitted.

[Table 6 about here]

[Table 7 about here]

\subsection{Risk preference or screening?}

If the positive correlation between self-assessed health and insurance was caused by heterogeneous risk preferences-i.e. that healthy individuals also were more risk-averse - then we would expect observable health conditions to increase the probability of insurance but to decrease self-assessed health. The first two columns of Table 8 show the results from the probit-regressions of Model 7 on the European and the American SHARE versions of self-assessed health. The third column shows the results from the ordered probit regression of Model 6, using insurance as a dependent variable.

[Table 8 about here]

Among the observable health conditions, cancer heart problems, chronic lung disease, and the number of chronic conditions all had statistically significant negative effects on self-assessed health in the European version. In the American version, diabetes also had a statistically significant negative effect (at the $10 \%$ level). The only observable health condition that actually turned out to have a positive effect on self-assessed health was high blood pressure.

Cancer had a statistically significant positive effect on the probability of holding insurance ( $\mathrm{p}$-value 0.063), while heart problems, diabetes, and chronic lung disease decreased the probability. Smoking and drinking appeared to increase the 
probability of holding insurance.

\section{Concluding remarks}

In this paper, we addressed the demand for voluntary health insurance in Europe. In similarity to other studies (Ettner, 1997; Hurd and McGarry, 1997; Smith and Kington, 1997; Perry and Rosen, 2004; Doiron et al., 2008), we found that individuals with a lower risk (measured as better self-assessed health) were more likely to have voluntary health insurance than relatively risky individuals. This is not consistent with what we would expect from the theory of adverse selection. A strand of research argues that such results are caused by unobservable factors, such as personality and risk preference, and that these factors are negatively correlated with self-assessed health. In contrast to some previous studies (Finkelstein and McGarry, 2003; Doiron et al., 2008), we did not find clear evidence of such a relationship.

The effects of observable health conditions on the probability of holding insurance and on self-assessed health are crucial for sorting out whether the correlation between health-risk and holding insurance was a result of risk preference among insured individuals or screening on behalf of the insurer. Ettner (1997), for instance, found mixed results with regards to individual conditions. Doiron et al. (2008) suggested that individuals with more long-term conditions were more likely to purchase insurance. In our study, high blood pressure actually turned out to have a positive effect on self-assessed health; the variable might capture some unobservable personal trait that tends to be correlated with high blood pressure, though. Since the coefficients of all other included health conditions had the expected signs, we believe that we could safely conclude that observable health conditions had a negative effect on self-assessed health.

Current smoking has certainly been found to be associated with a lower rate of 
health insurance (Ettner, 1997; Doiron et al., 2008), but individuals who have been smoking in the past may not be either more or less prone to have supplemental health insurance (Hurd and McGarry, 1997). In our study, smoking (and drinking) appeared to increase the probability of holding insurance. Most observable health conditions seemed to decrease the probability, though. Thus, we did not find any evidence that unambiguously supports the hypothesis that heterogeneous risk preferences are behind the observed negative correlation between risk and insurance.

Obviously, there may be some other factor influencing both health and the propensity to hold health insurance. The quest for such a factor, as well as the analysis of the effect of the explanatory variables on the demand for health insurance can be performed within an extended demand-for-health framework. Firmly founded on neoclassical economic theory, the demand-for-health model (Grossman, 1972a, b) remains the dominating theoretical model for analyzing the demand for health (and health investments). Afundamental idea behind the model is that the demand for medical care is derived from the more fundamental demand for health. Likewise, in an extended demand-for-health framework, it seems reasonable to think about the demand for health insurance not as a demand for insurance per se, but as derived from the demand for health. However, no extension of the demand-for-health model that incorporates the (derived) demand for health insurance has been published, even though this originally deterministic model has certainly been extended to include various types of uncertainty (see, for instance, Chang, 1996; Liljas, 1998). It goes beyond the purpose of this paper to develop a formal extension of Grossman's model, which incorporates the demand for health insurance. However, it is possible to use a somewhat heuristic approach, applying the fundamentals of the demand-for-health model to the demand for health insurance without a specific model-adaption to the insurance problem.

Thus, as regards an alternative explanation for the observed positive correlations 
between health and health insurance, the demand-for-health framework contains a plausible candidate: time preferences. An individual who does not discount future wellbeing at all, for instance, will demand more health than another individual who discounts future wellbeing, ceteris paribus. Likewise, no discounting of future wellbeing means that the expected payoff from holding health insurance and, hence, the present value of health insurance, will be higher than when future outcomes are discounted. Consequently, time preferences may be responsible for the observed correlation between risk and insurance.

The effects of the three central explanatory variables of the Grossman modelage, wage, and education - on the demand for health insurance can be inferred as follows. First, as the individual gets older the likelihood of adverse health shocks becomes higher and, hence, strengthens the incentive for holding health insurance; Second, a higher wage rate means that the present value of health insurance increases, since the potential losses of income are larger when the wage rate is higher; Third, more education means enhanced labor-market opportunities and, hence, an individual who has a university degree will put a higher value on health insurance than a comparable individual with less education.

Education, being female, being married, and being self-employed, all increased the probability of holding insurance, while being foreign born decreased the probability. Non-significant negative coefficients were found for age and being unemployed. With a couple of exceptions, the results are in line with previous research (Ettner, 1997; Hurd and McGarry, 1997; Smith and Kington, 1997; Perry and Rosen, 2004; and Doiron et al., 2008). First, a common finding of previous research is that people who have voluntary health insurance tend to be younger than those who do not (Ettner, 1997; Doiron et al., 2008); we could not identify a significant effect of age. Second, whereas our study showed the expected positive sign for self-employment, Perry and Rosen (2004) found that self-employment reduced the probability of having health insurance in the U.S. Given the "more to lose" rationale, this might seem surprising, but their results should obviously be 
seen in the light of the fact that American health insurance generally is tied to employment. We found no statistically significant effect of wealth, whereas a positive correlation between wealth (or income) and insurance was found in several previous studies (Ettner, 1997; Hurd and McGarry, 1997; Smith and Kington, 1997; Perry and Rosen, 2004; and Doiron et al., 2008).

Health insurance provides the text-book example of a market with adverse selection. Yet, there is little or no evidence in practice that adverse selection is or must be an important problem in health insurance. Health-insurance markets seem to be stable, despite the prediction of the Rotschild-Stiglitz model either that an equilibrium would not exist or that the equilibrium would be characterized by high health-risks buying full insurance and low risks buying incomplete coverage. It is difficult, however, to define a strong test for the presence of adverse selection in health insurance (Pauly, 1986). We did not find any support in our study—on the contrary. In line with previous studies, we found a negative correlation between health-risk and health insurance. The explanation did not appear to be heterogeneous risk-preferences of the insured but more likely that insurers were able to offer more attractive contracts to low-risk individuals, by discriminating on the basis of observable characteristics. 


\section{References}

Bolin, K., Lindgren, A., Lindgren, B. \& Lundborg, P. (2009). Utilisation of physician services in the $50+$ population: the relative importance of individual versus institutional factors in 10 European countries. International Journal of Health Care Finance \& Economics, 9, 83-112.

Bolin, K., Lindgren, B. \& Lundborg, P. (2008). Your next of kin or your own career. Caring and working among the 50+ of Europe. Journal of Health Economics, 27, 718-738.

Bonsang, E. (2009). Does informal care from children to their elderly parents substitute for formal care in Europe? Journal of Health Economics 28. 143-54.

Börsch-Supan, A. \& Jürges, H. (2005). The Survey of Health, Ageing and Retirement in Europe - Methodology. Mannheim Research Institute for the Economics of Aging.

Buber, I. \& Engelhardt, H. (2008). Children's impact on the mental health of their older mothers and fathers. Findings from SHARE. European Journal of Ageing 5(1): 31-45.

Cawley, J.\& Philipson, T. (1999). An empirical examination of information barriers to trade in insurance. American Economic Review, 89, 827-846.

Chang, F. (1996). Uncertainty and investment in health. Journal of Health Economics, 15, 369-376.

Chiappori P.A. \& Salanie, B. (2000). Testing for asymmetric information in insurance markets. Journal of Political Economy, 108, 56-78.

Clark, P.M. \& Ryan, C. (2006). Self-reported health: Reliability and consequences for health inequality measurement. Health Economics, 15, 645-652.

Crossley, T.F. \& Kennedy, S. (2002). The reliability of self-assessed health status. Journal of Health Economics, 21, 643-658.

Doiron, D., Jones, G. \& Savage, E. (2008). Healthy, wealthy and insured? The role of self-assessed health in the demand for private health insurance. Health Economics, 17, 317-334.

Ettner, S.L. (1997). Adverse selection and the purchase of Medigap insurance by the elderly. Journal of Health Economics, 16, 543-562. 
Finkelstein, A. \& McGarry, K. (2003). Private information and its effect on market equilibrium: New evidence from long-term care insurance. NBER Working Paper 9957. Cambridge, MA: National Bureau of Economic Research.

Finkelstein, A. \& Poterba, J. (2004). Adverse selection in insurance markets: Policyholder evidence from the U.K. annuity market. Journal of Political Economy, 112, 183-208.

Gerdtham, U.G., Johannesson, M., Lundberg, L. \& Isacson, D. (1999). A note on validating Wagstaff and van Doorslaer's health measure in the analysis of inequalities in health. Journal of Health Economics, 18, 117-124.

Grossman, M. (1972a). The demand for health: A theoretical and empirical investigation. New York: National Bureau of Economic Research, Occasional Paper 119.

Grossman, M. (1972b). On the concept of health capital and the demand for health. Journal of Political Economy, 80, 223-225.

Hurd, M.D. \& McGarry, K. (1995). Evaluation of the subjective probabilities of survival in the health and retirement study. Journal of Human Resources, 30, 268292.

Hurd, M.D. \& McGarry, K. (1997). Medical insurance and the use of health care by the elderly. Journal of Health Economics, 16, 129-154.

Jürges, H. (2009). Healthy minds in healthy bodies. An international comparison of education-related inequality in physical health among older adults. Scottish Journal of Political Economy, forthcoming.

Klevmarken, A. \& Lindgren, B. (2008). An ageing economy in an international perspective. In A. Klevmarken \& B. Lindgren (Eds.) Simulating an ageing population. A microsimulation approach applied to Sweden (pp. 1-29). Contributions to Economic Analysis 285. Bingley, UK: Emerald.

Liljas, B. (1998). The demand for health with uncertainty and insurance. Journal of Health Economics, 17, 153-170.

Lokshin, M. \& Ravallion, M. Rich and powerful? Subjective power and welfare 
in Russia. Journal of Economic Behavior and Organization, 56, 141-172.

Maurer, J. (2009). Who has a clue to preventing the flu? Unraveling supply and demand effects on the take-up of influenza vaccinations. Journal of Health Economics, doi:10.1016/j.jhealeco.2009.01.005.

OECD (2004). Private health insurance in OECD countries. Paris: OECD.

Pauly, M.V. (1986). Taxation, health insurance, and market failure in the medical economy. Journal of Economic Literature, XXIV, 629-675.

Perry, C. \& Rosen, H.S. (2004). The self-employed are less likely to have health insurance than wage earners. So what? In D. Holtz-Eakin \& H.S. Rosen (eds), Public Policy and the Economics of Entrepreneurship. Cambridge, MA: MIT Press.

Rothschild, M. \& Stiglitz, J. (1976). Equilibrium in competitive insurance markets: An essay on the economics of imperfect information. Quarterly Journal of Economics, 90(4): 629-49.

Schut, F.T. \& Van de Ven, W.P.M.M. (2005). Rationing and competition in the Dutch health-care system. Health Economics, 14, S59-S74.

Shmueli, A. (2001). The effect of health on acute care supplemental insurance ownership: an empirical analysis. Health Economics, 10, 341-350.

Siciliani, L. \& Verzulli, R. (2009). Waiting times and socioeconomic status among elderly Europeans: Evidence from SHARE. Health Economics (forthcoming).

Smith, J.P. \& Kington, R.S. (1997). Race, socioeconomic status, and health in late life. In L. Martin and B. Soldo (eds.), Racial and Ethnic Differences in the Health of Older Americans. National Academy Press: Washington, DC.

Solé-Auró, A. \& Crimmins, E.M. (2008). Health of immigrants in European countries. International Migration Review 42(4): 861-76.

Wagstaff, A. \& van Doorslaer, E. (1994). Measuring inequalities in health in the presence of multiple-category morbidity indicators. Health Economics, 3, 281289.

Verropoulou, G. \& Tsimbos, C. (2007). Socio-demographic and health-related 
factors affecting depression of the Greek population in later life: an analysis using SHARE data. European Journal of Ageing 4(3): 171-181. 


\begin{tabular}{|llll|llll|}
\hline Country & Total & VHI & $\mathbf{0}$ & Country & Total & VHI & $\mathbf{\%}$ \\
\hline Austria & 1887 & 394 & 20.9 & Greece & 2895 & 118 & 4.1 \\
Belgium & 3817 & 2419 & 63.4 & Italy & 2550 & 88 & 3.5 \\
Denmark & 1702 & 407 & 23.9 & Spain & 2379 & 181 & 7.6 \\
France & 3112 & 2448 & 78.7 & Sweden & 3045 & 67 & 2.2 \\
Germany & 3003 & 319 & 10.6 & Switzerland & 1000 & 252 & 25.2 \\
\hline
\end{tabular}

Table 1: Voluntary health insurance coverage by country. 


\begin{tabular}{|c|c|c|c|c|c|}
\hline \multicolumn{6}{|l|}{ SAH variables } \\
\hline Variable & & Mean & Variable & & Mean (S.D.) \\
\hline Very good health (EU) & 1 if very good SAH in EU version & 0.186 & Excel. health (US) & 1 if excellent SAH in US version & 0.101 \\
\hline Good health $(\mathrm{EU})$ & 1 if good SAH in EU version & 0.433 & Very good health & 1 if very good SAH in US version & 0.211 \\
\hline Fair health (EU) & 1 if fair SAH in EU version & 0.282 & Good health (US) & 1 if good SAH in US version & 0.391 \\
\hline Bad health (EU) & 1 if bad SAH in EU version & 0.078 & Fair health (US) & 1 if fair health in US & 0.225 \\
\hline Very bad health (EU) & 1 if bad SAH in EU version & 0.021 & Poor health (US) & 1 if poor health in US version & 0.071 \\
\hline \multicolumn{6}{|l|}{ Demographics } \\
\hline Variable & & Mean & Variable & & Mean \\
\hline Secondary education & 1 if secondary education & 0.297 & Wealth $10^{\text {th }}$ & 1 if wealth within $10^{\text {th }}$ percentile & 0.154 \\
\hline$>$ Secondary education & 1 if higher than secondary educ. & 0.187 & Wealth $25^{\text {th }}$ & 1 if wealth within $25^{\text {th }}$ percentile & 0.252 \\
\hline Female & 1 if respondent female & 0.558 & Wealth $50^{\text {th }}$ & 1 if wealth within $50^{\text {th }}$ percentile & 0.248 \\
\hline Married & 1 if respondent married & 0.699 & Wealth $75^{\text {th }}$ & 1 if wealth within $75^{\text {th }}$ percentile & 0.148 \\
\hline Foreign born & 1 if born outside survey country & 0.085 & Wealth $90^{\text {th }}$ & 1 if wealth within $90^{\text {th }}$ percentile & 0.096 \\
\hline Self employed & 1 if self-employed & 0.070 & & & \\
\hline \multicolumn{6}{|l|}{ Health and risk } \\
\hline Variable & & Mean & Variable & & Mean \\
\hline Heart problems & 1 if ever had heart problems & 0.119 & Smoking & 1 if ever been smoking & 0.457 \\
\hline Diabetes & 1 if respondent has diabetes & 0.095 & Alcohol > 5/week & 1 if alcohol $>5$ times/week & 0.243 \\
\hline Asthma & 1 if respondent has asthma & 0.046 & Exercise & 1 if phys. activity at least 1 & 0.583 \\
\hline High blood pressure & 1 if high blood pressure & 0.315 & Depression & 1 if felt depressed last month & 0.379 \\
\hline Number of chronic & Number of chronic symptoms & $1.52(1.43)$ & & & \\
\hline \multicolumn{6}{|l|}{ Country dummies } \\
\hline Variable & & Mean & Variable & & Mean \\
\hline Austria & 1 if resp from Austria & 0.074 & Greece & 1 if resp from Greece & 0.114 \\
\hline Belgium & 1 if resp from Belgium & 0.150 & Italy & 1 if resp from Italy & 0.100 \\
\hline Denmark & 1 if resp from Denmark & 0.067 & Spain & 1 if resp from Spain & 0.094 \\
\hline France & 1 if resp from France & 0.123 & Sweden & 1 if resp from Sweden & 0.120 \\
\hline Germany & 1 if resp from Germany & 0.118 & Switzerland & 1 if resp from Switzerland & 0.039 \\
\hline
\end{tabular}




\begin{tabular}{|lll|lll|}
\hline SAH (EU) & Number & \% VHI & SAH (US) & Number & \% VHI \\
\hline Very good & 4718 & 28.3 & Excellent & 2568 & 28.7 \\
Good & 11002 & 29.8 & Very good & 5359 & 26.8 \\
Fair & 7153 & 22.7 & Good & 9943 & 28.1 \\
Bad & 1984 & 18.4 & Fair & 5719 & 23.6 \\
Very bad & 536 & 17.5 & Poor & 1801 & 22.0 \\
\hline Total & 25390 & 26.4 & Total & 25390 & 26.4 \\
\hline
\end{tabular}

Table 3: Insurance coverage by different levels of self-assessed health. Left panel shows European scale, right panel shows American scale. 


\begin{tabular}{|l|c|c|c|c|c|}
\hline Variable & Model 1 & Model 2 & Model 3 & Model 4 & Model 5 \\
\hline Very good health & $0.173^{* * *}(0.009)$ & $0.242^{* * *}(0.009)$ & $0.094^{* * *}(0.010)$ & $0.205^{* * *}(0.009)$ & $0.095^{* * *}(0.010)$ \\
\hline Good health & $0.217^{* * *}(0.007)$ & $0.142^{* * *}(0.007)$ & $0.060^{* * *}(0.007)$ & $0.115^{* * *}(0.007)$ & $0.056^{* * *}(0.007)$ \\
\hline Bad health & $-0.153^{* * *}(0.011)$ & $-1.61^{* * *}(0.011)$ & $-0.119^{* *}(0.011)$ & $-0.145^{* * *}(0.011)$ & $-0.119^{* * *}(0.011)$ \\
\hline Very bad health & $-0.185^{* * *}(0.019)$ & $-0.249^{* * *}(0.017)$ & $-0.194^{* *}(0.018)$ & $-0.217^{* * *}(0.018)$ & $-0.187^{* *}(0.018)$ \\
\hline $\mathrm{N}$ & 25390 & 25390 & 25390 & 25390 & 25390 \\
\hline Control variables & & Countries & Countries & Countries & Countries \\
\hline & & & Demographics & Demographics \\
\hline & & & Health \& risk & Health \& risk \\
\hline
\end{tabular}

Table 4: Probit regression results, “European” version. Coefficients represent marginal effects.

\begin{tabular}{|l|c|c|c|c|c|}
\hline Variable & Model 1 & Model 2 & Model 3 & Model 4 & Model 5 \\
\hline Excellent health & $0.017(0.010)$ & $0.158^{* * *}(0.011)$ & $0.073^{* *}(0.010)$ & $0.144^{* * *}(0.011)$ & $0.081^{* *}(0.010)$ \\
\hline Very good health & $-0.041^{*}(0.007)$ & $0.077^{* * *}(0.008)$ & $0.014(0.007)$ & $0.065^{* * *}(0.008)$ & $0.016(0.008)$ \\
\hline Fair health & $-0.141^{* * *}(0.007)$ & $-0.147^{* * *}(0.007)$ & $-0.072^{* *}(0.007)$ & $-0.120^{* * *}(0.007)$ & $-0.068^{* *}(0.007)$ \\
\hline Poor health & $-0.225^{* * *}(0.010)$ & $-0.288^{* * *}(0.009)$ & $-0.182^{* *}(0.010)$ & $-0.248^{* * *}(0.010)$ & $-0.180^{* * *}(0.011)$ \\
\hline $\mathrm{N}$ & 25390 & 25390 & 25390 & 25390 & 25390 \\
\hline Control variables & & Countries & Countries & Countries & Countries \\
\hline & & & Demographics & Demographics \\
\hline
\end{tabular}

Table 5: Probit regression results, "American" version. Coefficients represent marginal effects. 


\begin{tabular}{|l|c|c|c|}
\hline Variable & Model 3 & Model 4 & Model 5 \\
\hline Very good health & $0.095^{* * *}(0.009)$ & $0.190^{* * *}(0.010)$ & $0.083^{* *}(0.009)$ \\
\hline Good health & $0.054^{* *}(0.007)$ & $0.113^{* * *}(0.007)$ & $0.048^{*}(0.007)$ \\
\hline Bad health & $-0.121^{* *}(0.011)$ & $-0.148^{* *}(0.011)$ & $-0.121^{* *}(0.011)$ \\
\hline Very bad health & $-0.201^{* *}(0.017)$ & $-0.226^{* *}(0.018)$ & $-0.198^{* *}(0.017)$ \\
\hline $\mathrm{N}$ & 25390 & 25390 & 25390 \\
\hline Control variables & Countries & Countries & Countries \\
\hline & Demographics & & Demographics \\
\hline & & Health \& risk & Health \& risk \\
\hline
\end{tabular}

Table 6: Probit regression results, including interaction variables controlling for institutional differences. "European" version, marginal effects.

\begin{tabular}{|l|c|c|c|}
\hline & Model 3 & Model 4 & Model 5 \\
\hline Excellent health & $0.069^{* *}(0.010)$ & $0.126^{* * *}(0.011)$ & $0.069^{*}(0.010)$ \\
\hline Very good health & $0.010(0.007)$ & $0.055^{*}(0.008)$ & $0.010(0.007)$ \\
\hline Fair health & $-0.056^{* *}(0.007)$ & $-0.120^{* * *}(0.007)$ & $-0.068^{* *}(0.007)$ \\
\hline Poor health & $-0.199^{* *}(0.010)$ & $-0.263^{* *}(0.010)$ & $-0.199^{* * *}(0.010)$ \\
\hline $\mathrm{N}$ & 25390 & 25390 & 25390 \\
\hline Control variables & Countries & Countries & Countries \\
\hline & Demographics & & Demographics \\
\hline & & Health \& risk & Health \& risk \\
\hline
\end{tabular}

Table 7: Probit regression results, including interaction variables controlling for institutional differences. "American" version, marginal effects. 


\begin{tabular}{|c|c|c|c|}
\hline Variable & SAH (EU) & SAH (US) & Prob(ins) \\
\hline Age & $-0.002^{* *}$ & $-0.002 * * *$ & -0.001 \\
\hline Secondary education & $0.273^{* * *}$ & $0.240 * * *$ & $0.359 * * *$ \\
\hline$>$ Secondary education & $0.505^{* * *}$ & $0.479 * * *$ & $0.516^{* * *}$ \\
\hline Female & $0.052^{* * *}$ & 0.021 & $0.064 * * *$ \\
\hline Married & $0.063^{* * *}$ & $0.074 * * *$ & $0.161^{* * *}$ \\
\hline Foreign born & $-0.125^{* * *}$ & $-0.104 * * *$ & $-0.247 * * *$ \\
\hline Self employed & $0.236^{* * *}$ & $0.197 * * *$ & $0.172 * * *$ \\
\hline Unemployed & -0.059 & $-0.068^{*}$ & -0.089 \\
\hline Cancer & $-0.146^{* * *}$ & $-0.158^{* * *}$ & $0.089 *$ \\
\hline Heart problems & $-0.194 * * *$ & $-0.183^{* * *}$ & $-0.088^{* *}$ \\
\hline Diabetes & -0.041 & $-0.048^{*}$ & $-0.081 * *$ \\
\hline High blood pressure & $0.155^{* * *}$ & $0.155^{* * *}$ & 0.018 \\
\hline Chronic lung disease & $-0.142^{* * *}$ & $-0.167 * * *$ & $-0.095^{*}$ \\
\hline Number of chronic symptoms & $-0.376 * * *$ & $-0.390 * * *$ & 0.004 \\
\hline Smoke & 0.002 & -0.013 & $0.071^{* * *}$ \\
\hline Drink & $0.138^{* * *}$ & $0.103^{* * *}$ & $0.086^{* * *}$ \\
\hline Exercise & $0.497 * * *$ & $0.497 * * *$ & $0.053^{* *}$ \\
\hline Austria & $0.231 * * *$ & $0.336^{* * *}$ & $0.513^{* * *}$ \\
\hline Belgium & $0.626^{* * *}$ & $0.600 * * *$ & $1.790 * * *$ \\
\hline Denmark & $0.483^{* * *}$ & $0.741 * * *$ & $0.529 * * *$ \\
\hline France & $0.404^{* * *}$ & $0.329 * * *$ & $2.254 * * *$ \\
\hline Greece & $0.477 * * *$ & $0.400 * * *$ & $-0.396 * * *$ \\
\hline Italy & $0.184^{* * *}$ & $0.238^{* * *}$ & $-0.409 * * *$ \\
\hline Spain & $0.297 * * *$ & $0.280 * * *$ & 0.058 \\
\hline Sweden & $0.599 * * *$ & $1.012^{* * *}$ & $-0.687 * * *$ \\
\hline Switzerland & $0.786^{* * *}$ & $0.622^{* * *}$ & $0.697 * * *$ \\
\hline
\end{tabular}

Table 8: Pooled regression results. Ordered probit regression on self-assessed health, probit regression on insurance. Only variables that were significant in any of the three regressions are reported. 